\title{
User involvment in the InvolvE study Diana Rose
}

Address: PO 34 Institute of Psychiatry, De Crespigny PArk, London, SE5 8AF, UK from WPA Thematic Conference. Coercive Treatment in Psychiatry: A Comprehensive Review Dresden, Germany. 6-8 June 2007

Published: 19 December 2007

BMC Psychiatry 2007, 7(Suppl I):S8I doi:10.1 186/I47I-244X-7-SI-S8I

This abstract is available from: http://www.biomedcentral.com/|47|-244X/7/SI/S8 I

(C) 2007 Rose; licensee BioMed Central Ltd.

Mental health service users were involved in the InvolvE study in two ways. Firstly, one of the principal investigators was a mental health service user. She regarded her job as keeping the study a user-focused one. Secondly, at each site, there was one user researcher and one non-user researcher. We were interested to see whether participants reacted to a peer interviewer differently to a non-peer interviewer. For example, did the presence of a peer interviewer enable the participant to be more open and relaxed or more inclined to voice criticism of their situation as detained patients subject to compulsory treatment. This paper will address these questions. 